\title{
Scientific Understanding, Fictional Understanding, and Scientific Progress
}

Park, Seungbae (2019). Journal for General Philosophy of Science

https://doi.org/10.1007/s10838-019-09480-8

pdf: $\quad$ https://link.springer.com/epdf/10.1007/s10838-019-09480-

$\underline{\text { 8?author access token=LuylEeSF4AvEkv6ZqahJdve4RwlQNchNByi7wbcMAY5R0OQ87f }}$ m8iiWsaSN39Phan8xBnu0iweJGRDY fOB kPNVMsTGfOma0auNKksIJeUIxvGUB8dJOS KWmJHdgIndZX9rl2HMwNkkGml-oX4WEGA\%3D\%3D

Seungbae Park

Ulsan National Institute of Science and Technology

The Republic of Korea

\begin{abstract}
The epistemic account and the noetic account hold that the essence of scientific progress is the increase in knowledge and understanding, respectively. Dellsén (2018) criticizes the epistemic account (Park, 2017a) and defends the noetic account (Dellsén, 2016). I argue that Dellsén's criticisms against the epistemic account fail, and that his notion of understanding, which he claims requires neither belief nor justification, cannot explain scientific progress, although it can explain fictional progress in science-fiction.
\end{abstract}

\section{Keywords}

Cognitive Episode, Means-End Thesis, Non-Cognitive Episode, Restriction Thesis

\section{Introduction}

This paper aims to defend the epistemic account (Park, 2017a) from Dellsén's critiques and raise difficulties against the noetic account (Dellsén, 2016, 2018). The epistemic account and the noetic account are different views about what scientific progress consists in. They hold that it consists in the increase in knowledge and understanding, respectively. The epistemic account was originally developed by Alexander Bird (2007). Throughout this paper, however, 'the epistemic account' refers to the variant developed by Park (2017a), given that his variant is the target of Dellsén's (2018) criticisms to which this paper responds.

In Section 2, I apply the epistemic account and the noetic account to two episodes in science to make explicit what they assert and to show that the epistemic account is more plausible than the noetic account from the scientist's point of view. In Section 3, I defend the epistemic account from Dellsén's criticism that it is ad hoc for Park to exclude non-cognitive episodes from the set of explananda that a philosophical theory of scientific progress should explain. In Section 4, I argue that Dellsén's notion of scientific understanding, which he claims requires neither belief nor justification, fits not an understanding in science but rather an understanding in science-fiction. So it cannot be invoked to explain scientific progress, although it can be invoked to explain fictional progress in science-fiction. It will become clear that the epistemic account remains unscathed from Dellsén's criticisms, and that the epistemic account is more promising than the noetic account.

\section{The Epistemic Account vs. the Noetic Account}

Park earlier defined the epistemic account as the view that "a cognitive episode in science is progressive, if and only if it involves the increase in knowledge or the acquisition of a means 
to increase knowledge" (Park, 2017a: 571). The first conjunct of this formulation implies that confirming true scientific theories constitutes scientific progress because we gain knowledge as a result of confirming them. The second conjunct, which Park (2017a: 570) calls the means-end thesis, implies that disconfirming false scientific theories also constitutes scientific progress, insofar as it serves as the means to confirm true scientific theories.

Let me apply the means-end thesis to two episodes in science. Let me begin with an episode illustrating that scientists often make failures and mistakes in the process of finding true hypotheses. In 1846, Ignaz Semmelweis (1818-1865) set out to explain why the mortality rate of the first maternity division was excessively high in the Vienna General Hospital (Hempel, 1966: 3-6). He tested five false hypotheses before arriving at the true hypothesis that cadaverous materials from autopsy were the cause of the problem. All of the five false hypotheses could not explain any phenomenon. On the epistemic account, however, the episode of testing them counts as scientific progress because it paved the way for the confirmation of the true hypothesis. Let me turn to an episode illustrating that scientists make failures and mistakes in the process of achieving intended experimental results. Cloning an animal is a complicated and delicate process of fusing nuclei with enucleated egg cells. Ian Wilmut's research team made about three hundred experimental failures before cloning a sheep in 1996 (Park, 2017b: 216). On the epistemic account, however, the episode of making the experimental failures counts as scientific progress because it served as a stepping stone for acquiring the knowledge of how to clone a sheep.

As Bird points out, present scientists acquired "the negative knowledge that some earlier theory is false" (Bird, 2007: 108). So we can say that scientists gain negative knowledge from failures and mistakes. In the process of eliminating the five false hypotheses, Semmelweis acquired the negative knowledge that the five factors that he considered were irrelevant to the deaths of the women who were delivering. In the process of making about three hundred experimental failures, Wilmut's research team obtained the negative knowledge that a sheep could not be cloned, if nuclei from a ewe were inserted into enucleated egg cells in certain manners. The negative knowledge was a means to achieve the positive knowledge, i.e., scientists were moving toward success little by little by making failures and mistakes. Consequently, making failures and mistakes in science constitute progress.

Park (2017a: 570-571) distinguishes between cognitive and non-cognitive episodes. A cognitive episode involves cognitive changes, whereas a non-cognitive episode does not. For example, proposing a new scientific theory, testing it, justifying it, and falsifying it are cognitive episodes, whereas scientists' receiving funding and maintaining good relations with their spouses are non-cognitive episodes. After distinguishing between cognitive and noncognitive episodes, Park advances the restriction thesis that "the debate over scientific progress is restricted to those episodes that involve cognitive changes" (Park, 2017a: 570). In other words, the target episodes that a philosophical theory of scientific progress should address are restricted to cognitive episodes. Thus, the epistemic account does not need to explain why a non-cognitive episode is promotive or demotive. It only needs to explain why a cognitive episode is regressive or progressive.

In contrast, Bird (2008: 280) and Dellsén (2018: 454) suggest that the increase in funding promotes scientific progress, given that it facilitates the production of knowledge and understanding. Park would agree with Bird and Dellsén that increasing funding promotes scientific progress. He would, however, insist that the epistemic account does not say anything about whether a non-cognitive episode promotes or demotes scientific progress. The contention that a non-cognitive episode promotes scientific progress is not part of a philosophical theory of scientific progress but rather part of a non-philosophical theory of 
scientific progress.

Let me provide the justification for the restriction thesis. The set of explananda that a theory of scientific progress should explain would be intractable and unmanageable, if noncognitive episodes are included in the set of the explananda. A theory of scientific progress, for example, would have to tell us whether and how scientists' maintaining good relationships with their spouses promotes scientific progress, scientists' breathing oxygen promotes scientific progress, scientists' eating food slowly promotes scientific progress, whether and how a particular vibration pattern of strings in extra dimensions promote scientific progress, and so forth. As a result, the theory of scientific progress would become a theory of nearly everything.

It is not a theory of scientific progress but rather a theory of something else that should address the issue of whether and how non-cognitive episodes promote scientific progress. For example, psychologists may develop a psychological theory of whether and how scientists' maintaining good relationships with their spouses promotes scientific progress. Nutrition scientists may develop a nutrient theory of whether and how eating food slowly promotes scientific progress. Similarly, science policy-makers may develop a policy theory of whether and how the increase in funding promotes scientific progress. Therefore, it is not the job of a philosophical theory of scientific progress to address the issue of whether and how the increase in funding promotes scientific progress.

Consider that the scope of evolutionary theory is restricted to biological phenomena, so it does not say anything about how the universe began. Critics of evolutionary theory, however, tend to ask questions about the origin of the universe in the context of the debate over whether evolutionary theory is tenable. When critics ask such questions, advocates of evolutionary theory should say that the origin of the universe falls outside the scope of evolutionary theory, and that it is not the job of evolutionary theory but rather a job of cosmological theory to answer questions about how the universe came to be. Analogously, theorists of scientific progress should say that non-cognitive episodes fall outside the scope of a theory of scientific progress, and that it is not the job of a philosophical theory of scientific progress but rather a job of something else to answer questions about whether and how noncognitive episodes promote scientific progress.

Let me now turn to the noetic account. It holds that "scientific progress consists in increasing understanding," and "an episode in science is progressive precisely when scientists grasp how to correctly explain or predict more aspects of the world at the end of the episode than at the beginning" (Dellsén, 2016: 73). For example, Copernican scientists explained certain phenomena, such as the phase of Venus, that Ptolemaic scientists could not. As a result, the former understood more aspects of the world than the latter, and hence scientific progress was made when the Copernican revolution was completed.

Let me apply the noetic account to the episodes of Semmelweis and Wilmut's team above. The noetic account implies that Semmelweis was not making any scientific progress when he was eliminating the five false hypotheses. After all, none of the five false hypotheses explained or predicted any phenomenon. The noetic account also implies that Wilmut's team was not making any scientific progress when they made about three hundred failed attempts to clone a sheep. After all, Wilmut's team was neither increasingly explaining nor predicting more phenomena when they were making the experimental mistakes and failures. Having rejected the means-end thesis, proponents of the noetic account cannot say that Semmelweis and Wilmut's team were making scientific progress when they made failed attempts.

I invite readers to imagine how Semmelweis and Wilmut's teams would respond to proponents of the epistemic account and proponents of the noetic account who say to them, respectively, "All of your attempts have so far failed, but you made scientific progress," and 
"All of your attempts have so far failed, so you didn't make any scientific progress." The scientists would say to proponents of the noetic account, "What progress do you think can come out of what you just told us?" It is sometimes useful for philosophers to imagine how scientists would respond to their philosophical views of science (Park, 2018a: 16-17, 2018b: 77). Philosophers should be ready to adequately to respond to scientists who hold the negative attitude toward their philosophical views of science.

\section{The Means-End Thesis and the Restriction Thesis}

Now that the key differences between the epistemic account and the noetic account have been outlined, we are ready to evaluate the debate between Park and Dellsén over the means-end thesis and the restriction thesis. Recall that the mean-end thesis states that a cognitive episode in science counts as scientific progress, if it involves "the acquisition of a means to increase knowledge" (Park, 2017a: 571). The restriction thesis states that "the debate over scientific progress is restricted to those episodes that involve cognitive changes" (Park, 2017a: 570).

Dellsén objects that the restriction thesis is "extremely ad hoc, since only a rationale for restricting the account in this way is that doing so is meant to avoid the aforementioned problem" (Dellsén, 2018: 452, footnote 3). By the aforementioned problem, he means that the means-end thesis has the absurd consequence that the episode of scientists' receiving funding counts as scientific progress. Park (2017a) tried to block this absurd consequence with the restriction thesis which implies that the episode of receiving funding falls outside the scope of a theory of scientific understanding. This, however, appears to be ad hoc to Dellsén.

On close examination, however, the restriction thesis is not ad hoc. In Section 2, I argued that without the restriction thesis, the scope of a theory of scientific progress becomes intractable. Moreover, further independent support for the restriction thesis ironically can be found in Ilkka Niiniluoto's (2015) observation that Dellsén approvingly cites, viz., "the traditional debate about scientific progress concerns the kind of progress that is made in science with regard to our theories' representation of the world" (Dellsén, 2018: 452). On Niiniluoto and Dellsén account, a philosophical theory of scientific progress is not about noncognitive scientific progress but rather about cognitive scientific progress. It is natural, then, to restrict its explananda to cognitive episodes.

It would be truly arbitrary to propose that a philosophical theory of scientific progress is only about cognitive scientific progress, but that it also should tell us whether a noncognitive episode is promotive or demotive. Why suddenly talk about non-cognitive episodes in the context of talking about cognitive scientific progress? Why include non-cognitive episodes in the set of target episodes that a philosophical account of cognitive scientific progress should address? Again, it is a non-philosophical account of scientific progress that should address the issue of whether a non-cognitive episode is promotive or demotive.

Let me use an analogy to argue that it is unreasonable to ask proponents of the epistemic account to determine whether a non-cognitive episode is promotive or demotive. Evolutionary theory and the Big Bang theory explain different phenomena. It is unreasonable to challenge evolutionary biologists to explain why the cosmic background radiation exists and to challenge cosmologists to explain why tigers are ferocious. Similarly, it is unreasonable to challenge proponents of the epistemic account to explain why a noncognitive episode is promotive or demotive. It is not ad hoc for evolutionary biologists to exclude the cosmic background radiation from the set of target phenomena that evolutionary theory should explain. Similarly, it is not ad hoc for Park to exclude non-cognitive episodes from the set of target episodes that a philosophical theory of cognitive scientific progress should explain.

Let me now turn to a thought experiment that Dellsén has constructed to reduce the 
means-end thesis and the restriction thesis to absurdity. Imagine that "a powerful new funding agency agrees to double the financial resources of an entire scientific discipline, e.g., evolutionary biology, but only on the condition that they all abandon (i.e. cease to accept or believe) the theory of natural selection and instead adopt (i.e., start believing or accepting) a pseudo-scientific theory, e.g. intelligent design" (Dellsén, 2018: 453). This episode is cognitive, so the restriction thesis cannot be invoked to exclude it from the set of explananda that the epistemic account should explain. Intuitively, this cognitive episode is regressive, but "this type of episode would count as progressive according to Park's expanded account" (Dellsén, 2018: 453).

This criticism against the means-end thesis and the restriction thesis initially may come off as clever, but there are problems with it. The episode described by Dellsén above consists of two sub-episodes. One sub-episode concerns replacing the theory of natural selection with the theory of intelligent design. The other sub-episode concerns doubling the financial resources. The epistemic account says that the first sub-episode is regressive. It, however, says nothing about whether the second sub-episode is regressive or progressive due to the fact that it is a non-cognitive episode. Hence, the epistemic account asserts that the first subepisode depicted by Dellsén above is regressive, contrary to the spirit of Dellsén's contention, and the epistemic account remains silent on the second sub-episode.

Before we determine whether the epistemic account implies that an episode is regressive or progressive, we should determine whether the episode is cognitive or noncognitive. To accuse the epistemic account of having the false consequence that a noncognitive episode is promotive is as objectionable as accusing evolutionary theory of having the false consequence that entropy does not increase on the Earth. The epistemic account is not designed to say anything about whether a non-cognitive episode is promotive or demotive any more than evolutionary theory is designed to say anything about whether the entropy on the Earth increases or decreases.

The means-end thesis and the restriction thesis remain unscathed vis-à-vis Dellsén's thought experiment above. Some of Dellsén's (2018) criticisms against the epistemic account are built on the problematic assumption that the means-end thesis and the restriction thesis are reduced to absurdity. Those criticisms concern Einstein's explanation of Brownian motion (Dellsén, 2018: 455), Wegener's continental drift theory (Dellsén, 2018: 455), idealizations (Dellsén, 2018: 458), and simplicity (Dellsén, 2018: 458). My responses to these criticisms can be extrapolated from my response to the problematic assumption sketched above, mutatis mutandis. So instead of wasting space in spelling out my responses to them, I turn to more important issues in the next section.

\section{Scientific Understanding vs. Fictional Understanding}

In this section, I argue that Dellsén's original notion of scientific understanding is not an adequate explanatory apparatus for scientific progress, and that it can only explain fictional progress in science-fiction.

Dellsén claims that an "agent has partial scientific understanding of a given target just in case she grasps how to correctly explain and/or predict some aspects of the target" (Dellsén, 2016: 75). For example, certain physicists understand the fundamental aspect of the world by explaining various natural phenomena in terms of string theory (Dellsén, 2017: 249). Dellsén also contends that "understanding requires neither belief nor justification" (Dellsén, 2017: 240). Given that an explanation consists of an explanandum and an explanans (or explanantia), his contention implies that an explanandum and an explanans neither need to be believed nor need to be justified. Yet, a scientific understanding arises from such an explanation, and such an understanding can be invoked to account for scientific progress. 
We can immediately see that this notion of scientific understanding is not adequate for explaining scientific progress, once we consider the following imaginary dialogue between two children:

Child 1: Who wins if Superman and Batman fight with each other?

Child 2: Of course, Superman wins. After all, he can lift up a heavy rock as large as a mountain. Moreover, he can fly. But Batman can do none of these things.

Child 1: No, Batman wins. He only needs to carry Kryptonite.

Child 2: I understand. (Park, 2017c: 384)

In this dialogue, the first child offered the explanation that Batman can defeat Superman because Batman can carry Kryptonite. As a result, the second child understands how Batman can defeat Superman. This understanding, however, is free of belief and justification. The children do not even believe that the explanandum and the explanans are true, so a question does not even arise as to whether they have the justification for the belief. Such an understanding has nothing to do with the world, i.e., it does not reflect the world. I call it $a$ fictional understanding. A fictional understanding is one that results from an explanation whose explanandum and explanans are neither believed nor justified.

A fictional understanding can be invoked to explain fictional progress in sciencefiction. Imagine again that the first child above previously claimed that Batman could beat Superman because Batman was a millionaire. This explanation, however, was not convincing to the second child, so he could not understand how Batman could defeat Superman. The first child now says that Batman can beat Superman because Batman only needs to have Kryptonite. This explanation is convincing to the second child, so he now understands how Batman can beat Superman. Note that progress is made in this science-fiction discussion, and that the progress is due to the increase in fictional understanding.

Scientists' understanding would become no different from the children's fictional understanding, if scientists did not believe that an explanandum and an explanans are true, and if they did not have the justification for the explanandum and the explanans. Thus, to explain scientific progress in terms of understanding devoid of belief and justification is to treat science as if it were science-fiction. If proponents of the noetic account find this contention disagreeable, they owe us an account of how scientists' understanding differs from the children's fictional understanding.

Proponents of the noetic account might reply that scientific explanations differ from fictional ones in that the former might be true, whereas the latter are false. ${ }^{1}$ Einstein's explanation of Brownian motion with the kinetic theory of gasses might be true, although we do not know that it is true. By contrast, the second child's explanation of how Batman can defeat Superman is false. In short, we can rule out the possibility that fictional explanations are true, but we cannot that scientific explanations are true.

It is questionable, however, whether we can rule out the possibility that a fictional explanation is true, given that scientists and engineers have made many electronic devices that first appeared in science-fiction films. I, however, set this minor point aside and grant that scientific explanations might be true, whereas fictional explanations are false. Dellsén claims that belief is not a component of understanding, which implies that he takes scientific understanding to be neither true nor false. So the understanding that results from Einstein's explanation of Brownian motion is still similar to the children's understanding of how

\footnotetext{
${ }^{1}$ I thank a reviewer for this comment.
} 
Batman can defeat Superman in that they are all neither true nor false.

Dellsén appeals to Jonathan Cohen's (1992) work on acceptance to cash out the notion of understanding. For Cohen, to accept $\mathrm{p}$ is to adopt "the policy of ... including $\mathrm{p}$ among one's premises for deciding what to do or think in a particular context" (Cohen, 1992: 4). By contrast, to believe $\mathrm{p}$ is to be "disposed to feel it true that p" (Dellsén, 2017: 248). For example, a lawyer feels that a defendant is guilty, but adopts the policy in court that the defendant is not guilty, i.e., she accepts, although she does not believe, that her client is not guilty. As a result, she thinks and speaks in court as if her client is not guilty, so that her client might be acquitted. Dellsén (2017: 248) appeals to this notion of acceptance, claiming that scientists only need to accept an explanandum and an explanans when they explain the explanandum in terms of the explanans, and that the explanation gives rise to an understanding. He says, "understanding something may merely involve treating certain propositions or theories as given in the context of explaining something, as opposed to being disposed to feel that the propositions or theories are true" (Dellsén, 2017: 248).

There is a problem with these notions of acceptance and understanding. Beliefs can be true or false, whereas acceptance only can be useful or useless. For example, it can only be useful or useless for a lawyer to adopt the policy that her client is not guilty. It follows that acceptance does not reflect the world, and nor does understanding (Park, 2017c: 384). Dellsén, then, owes us an account of how understanding differs from misunderstanding (Park, 2017c: 386). He cannot propose that understanding matches up with the world whereas misunderstanding does not because he earlier claimed that understanding does not embed belief but acceptance and because, as I claimed earlier, acceptance can only be useful or useless. It does not even make sense to say that a hammer, which can be useful or useless, matches up or does not match up with the world.

Moreover, the two children above merely accept the explanandum and the explanans. They accept that Batman can defeat Superman, and that Batman can carry Kryptonite, for the purpose of explaining the explanandum in terms of the explanans, deriving fun from such an explanation, and so on. They, however, do not feel that the explanandum and the explanans are true. Since they do not believe that the explanandum and the explanans are true, a question does not even arise as to whether they have the justification for the belief. Thus, appealing to the notion of acceptance does not help proponents of the noetic account escape from the charge that to rid belief and justification from scientific understanding is to reduce scientific understanding to fictional understanding.

What would happen in science if scientists do not believe that an explanandum is true, and yet they explain it in terms of their pet hypothesis? Park claims that "a tragic result may occur" (Park, 2017a: 572). Imagine that scientists submit a manuscript to a scientific journal. In the manuscript, they propose a hypothesis to explain certain data. They state, however, that they do not believe the data, and that they rather accept them, i.e., that they merely present them for the purpose of explaining them in terms of their pet hypothesis. How would editors respond to the authors? They would certainly execute a desk reject, saying, "If you don't believe your data, why would I believe them? Your manuscript doesn't deserve serious consideration." The editors might even accuse the authors "of having fabricated data, a serious violation of research ethics in science" (Park, 2017a: 572-573). This thought experiment is intended to confute Dellsén's suggestion that scientists can explain an explanandum with the mere acceptance that it is true.

How does Dellsén (2018) respond to Park's foregoing contention that scientists believe that their explanandum is real when they explain it by appealing to their scientific theory? $\mathrm{He}$ says that Park's contention is almost certainly false: 
Park also claims that "[w]hen scientists explain something in terms of a scientific theory, they believe that it [viz. the explanandum] is real" (Park 2017: 573). This appears to be an empirical claim about all scientists' mental states when engaging in a specific activity, viz., explanation. If so, it is almost certainly false given the existence of openly antirealist scientists, such as Niels Bohr, who surely engaged in the practice of explaining various phenomena even though they did not believe that the relevant theories were true... (Dellsén, 2018: 454)

Note that Dellsén confounds an explanandum with an explanans. Park was claiming that scientists believe that their explanandum is real. Dellsén, however, interprets Park as claiming that their explanatory theory is true, and then objects that some antirealist scientists do not believe that their explanatory theory is true.

Let me now present a thought experiment to show how problematic it is to speak in accordance with the mere acceptance of some propositions (Park, 2018c: 35). Imagine that a witness testifies in court, "I saw the defendant committing murder. Therefore, the defendant is guilty. I, however, don't believe the defendant committed murder. Nor do I believe she is guilty. I merely accept these two propositions for the purpose of making an inference from the first proposition to the second one." Note that this witness's verbal behavior perfectly fits Cohen and Dellsén's definition of acceptance quoted above. How would the judge respond to the witness? The judge would say, "You must be joking! You only wasted the litigants' time." A moral is that it may be inappropriate to speak in accordance with the acceptance of some propositions in serious enterprises, such as trials and science, although it might be appropriate in non-serious enterprises, such as science-fiction, comedies, and mythologies.

Imagine that noetic scientists explain the explanandum in terms of the explanans with the mere acceptance that they are true. They say, "This region of spacetime expanded and contracted because gravitational waves passed through it. But I neither believe this region of spacetime expanded and contracted, nor believe gravitational waves passed through it. I merely accept these two propositions to make an inference from one proposition to the other." How would metaphysicians respond to these noetic physicists? They will say, "What a wonderful inference! But did this region of spacetime expand and contract? Did gravitational waves pass through it? What I want to know is not whether one proposition follows from the other or not, but rather whether this region of spacetime expanded and contracted or not, and whether gravitational waves passed through it or not. Your inference doesn't give me any clue about what the world is like. Are you a scientist or a science-fiction writer?"

Proponents of the noetic account should take this complaint seriously, given that the noetic physicists' inference is similar to the witness's inference and to the children's inference above in that they merely accept some propositions. As a result, the noetic physicists' inference does not reflect the world any more than the children's inference and the witness's inference do. Moreover, just as the witness fails to distinguish between trial and comedy, so noetic physicists fail to distinguish between science and science-fiction. It is not clear whether such physicists exist. Therefore, understanding, as defined by Dellsén, only can explain fictional progress in science-fiction, and it certainly cannot explain scientific progress.

Let me now turn to an interesting question: Can scientists believe the explanandum, but merely accept the explanans? Dellsén's answer is "Yes." He appeals to Bas van Fraassen's notion of acceptance to defend his previous position that scientific understanding requires not belief but rather acceptance. He says, "In scientific context, i.e. when someone is asked for their opinion qua scientist (or, as van Fraassen (1980: 12) puts it, when the scientist is speaking ex cathedra), the answer would reflect what they accept rather than what they believe" (Dellsén, 2018: 454). Thus, according to Dellsén and van Fraassen, scientists can explain phenomena by merely accepting that an explanatory theory is true. Along with 
Dellsén and van Fraassen on this count are other philosophers, such as Gregory Dawes (2013: 68) and Rasmus Winther (2009: 376). These philosophers' view is popular among scientific antirealists.

Their view, however, can be undermined by the following two considerations. First, if scientists believe the explanandum, but merely accept the explanans, they would face the disconcerting objection that "it is a double standard to believe that an explanandum is true while merely accepting that an explanans is true" (Park, 2017c: 383). The double standard cannot be justified by the suggestion that an explanandum is an observational statement whereas an explanans is a theoretical statement. After all, in certain cases, both an explanandum and an explanans are theoretical statements in science. For example, physicists say today that gravitational waves were created because two black holes were merged. We cannot observe gravitational waves, so it is not an observational statement but rather a theoretical statement that gravitational waves were created. If physicists merely accept the explanans that two black holes were merged, they should also merely accept the explanandum that gravitational waves were created, thereby reducing their scientific explanation to a fictional one and reducing the scientific understanding to a fictional one. Science-fiction writers might be interested in such explanations, but metaphysician would not be.

Second, imagine that a medical doctor says, "Jill got diabetes because her pancreas doesn't generate insulin." We ask him whether he believes that Jill's pancreas does not generate insulin. He answers, "I don't believe Jill's pancreas doesn't generate insulin, but I accept Jill's pancreas doesn't generate insulin." Such an answer would only puzzle us. Our puzzlement stems from the fact that he is caught in Moore's paradox. The paradox occurs when you assert a Moorean sentence, 'P, but I don't believe p' (Moore, 1993: 207-212). In other words, it occurs when you declare that you do not believe what you just asserted. A Moorean sentence is included in the doctor's sentence, 'Jill got diabetes because her pancreas doesn't generate insulin, but I don't believe Jill's pancreas doesn't generate insulin, although I accept Jill's pancreas doesn't generate insulin.' Thus, the notion of acceptance does not help Dellsén, van Fraassen, Winther, and Dawes escape from Moore's paradox (Park, 2017c: 383, 2018c: 33-34; 2019: Section 4).

What should scientists' peers do when scientists appeal to a scientific theory to explain something? Dellsén says that their peers "should let their judgment on this question be determined by their estimation of whether the scientists' attitude toward the theory (be it acceptance or belief) is based on sufficient evidence, sound methodology, and so forth" (Dellsén, 2018: 454). In other words, when scientists put forward an argument for a scientific theory, their peers should evaluate the argument and determine whether the scientists' attitude, which might be acceptance or belief, is grounded on sufficient evidence or not. On this account, scientists' attitude toward a scientific theory might be belief, and their peers might judge whether the scientists' belief is justified or not. Thus, their peers might have the justification for the belief of a scientific theory.

To say so, however, is a significant retreat from the noetic account. Dellsén originally contended that "understanding requires neither belief nor justification" (Dellsén, 2017: 240), and that scientific understanding can be invoked to account for scientific progress. He now contends that scientists and their peers might have the justification for the belief of a scientific theory. Thus, Dellsén initially kicked out the notions of belief and justification through the front door, but he now invites them in through the back door. It is costly for him to invite them back, given that they are the essential components of knowledge and central to the epistemic account. Proponents of the epistemic account can say, while proponents of the noetic account cannot, that the production and proliferation of justified beliefs amongst 
scientists are significant steps toward scientific progress.

Let me now raise an objection to a thought experiment that Dellsén has constructed to distinguish between belief and acceptance. Imagine that there is a "deeply religious evolutionary biologist who cannot bring herself to believe the theory of natural selection, but nevertheless accepts it" (Dellsén, 2018: 454). She believes that all different species were independently created by God, but accepts that all different species have descended from a common ancestor, and then presents the scientific evidence in favor of evolutionary theory. What should her peers do? Dellsén would say that they should evaluate her argument, and then determine their attitude toward evolutionary theory depending on whether her argument is powerful or not.

Let me bring out two problems with Dellsén's suggestion. First, Moore's paradox might occur when the biologist presents her case for the theory of natural selection to her peers and then declare that she does not believe the theory of natural selection. Second, her peers might ask her some perplexing questions: "Do you believe what you just said? If you don't, why should I believe what you don't? How can you say to me what you don't believe? Do you expect me to believe what you don't?" (Park, 2019: Section 4). It is not clear how she would answer these questions. She might say that her peers should believe that the evolutionary view is true because her argument is powerful. If she says so, however, her peers would ask another bewildering question: "If you believe that your argument is powerful, why don't you believe first that the theory of natural selection is true?" A moral is that an argument lacks persuasive force, if its author does not believe it (Park, 2018c: 35). If you constructed an argument, you are a leader with respect to the argument. You should do what you expect other people to do when they hear your argument. Otherwise, they might not follow you. In other words, if you merely accept that the conclusion of your argument is true, they might also merely accept that the conclusion is true.

In certain contexts, it might even be unethical merely to accept some propositions and speak in accordance with the acceptance of the propositions (Park, 2018c: 35). Imagine that the aforesaid biologist is tried in court. Her political adversary brought a serious false charge to her. The biologist states in court that she did not commit the crime. The judge, however, thinks that the biologist accepts that she did not commit the crime, in spite of believing that she committed the crime. In addition, the judge accepts, although she does not believe, that the biologist committed the crime. As a result, the judge solemnly says, "I hereby sentence you to death." The defendant protests that it is preposterous for the judge to say such a sentence. The judge replies that she merely spoke in accordance with her acceptance that the defendant is guilty.

As this tragic thought experiment illustrates, it is even unethical in certain contexts to speak in accordance with the mere acceptance of some propositions. Thus, proponents of the noetic account and scientific antirealists who want to salvage the notion of acceptance would have to provide an account detailing in what contexts we are allowed and disallowed to speak in accordance with the mere acceptance of some propositions. In addition, they would have to provide an account of why speaking in accordance with the mere acceptance of a scientific theory belongs to the former category.

Finally, let me construct a short story that might be amusing to some readers of this paper. Once upon a time, there was a philosophy professor. One day, she hit upon the noetic account in her office. The more she pondered it, the more it sounded convincing to her. She was so excited about it that she presented it to her students during the philosophy class. Her students seemed to be persuaded of the noetic account. They stated openly, "Understanding, even if devoid of belief and justification, can account for scientific progress." She was quite happy to hear her students speaking the noetic language. Unfortunately, however, her students 
were staunch proponents of the epistemic account deep in their minds. They firmly believed that only an increase in knowledge could account for scientific progress. They, however, had the purpose ex cathedra to receive good grades from their professor. As a result, they accepted the claim that only an increase in understanding could account for scientific progress.

\section{Conclusion}

The means-end thesis holds that a cognitive episode is progressive insofar as it serves as a means to come by knowledge. The restriction thesis holds that the explananda of a philosophical theory of scientific progress are restricted to cognitive episodes. It is reasonable to exclude non-cognitive episodes from the set of the explananda, given that the set of the explananda would become intractable without the restriction, and given that a philosophical theory of scientific progress is not about non-cognitive scientific progress but rather about cognitive scientific progress.

Dellsén insists that "understanding requires neither belief nor justification" (2017: 240), and that acceptance can take the place of belief. I replied that to rid scientific understanding of belief and justification is to relegate it to fictional understanding and demote science to science-fiction. Scientific understanding, as defined by Dellsén, can be found not in science but rather in science-fiction, so it cannot be used to explain scientific progress, although it can be used to explain fictional progress in science-fiction.

I conclude this paper with a slogan: "Science is a serious enterprise." This slogan applies not only to proponents of the noetic account but also to scientific antirealists, such as van Fraassen, who contend that scientists only need to accept rather than believe scientific theories to explain phenomena.

\section{References}

Bird, Alexander (2007). "What is Scientific Progress?” Nô̂s 41 (1): 64-89.

(2008). "Scientific Progress as Accumulation of Knowledge: A Reply to Rowbottom", Studies in History and Philosophy of Science 39 (2): 279-281.

Cohen, L. Jonathan (1992). An Essay on Belief and Acceptance. Oxford: Oxford University Press.

Dawes, Gregory (2013). "Belief is Not the Issue: A Defence of Inference to the Best Explanation", Ratio: An International Journal of Analytic Philosophy 26 (1): 62-78.

Dellsén, Finnur (2016). "Scientific Progress: Knowledge vs. Understanding", Studies in History and Philosophy of Science 56: 72-83.

(2017). "Understanding without Justification or Belief", Ratio: An International Journal of Analytic Philosophy 30: 239-254.

(2018). "Scientific Progress, Understanding, and Knowledge: Reply to Park", Journal for General Philosophy of Science 49 (3): 451-459.

Hempel, Carl (1966). Philosophy of Natural Science. New Jersey: Prentice-Hall.

Moore, George (1993). "Moore's Paradox", In G.E. Moore: Selected Writings. Baldwin, 
Thomas (ed.), London: Routledge.

Niiniluoto, Ilkka (2015). "Scientific Progress", The Stanford Encyclopedia of Philosophy. Edward N. Zalta (ed.), URL $<$ https://plato.stanford.edu/archives/sum2015/entries/scientific-progress/>.

Park, Seungbae (2017a). "Does Scientific Progress Consist in Increasing Knowledge or Understanding?", Journal for General Philosophy of Science. 48 (4): 569-579.

(2017b). "The Uniformity Principle vs. the Disuniformity Principle", Acta Analytica 32 (2): 213-222.

(2017c). "Understanding without Justification and Belief?" Principia: An International Journal of Epistemology 21(3): 379-389. 17: 7-19.

(2018a). "The Grand Pessimistic Induction", Review of Contemporary Philosophy (2018b) “The Pessimistic Induction and the Golden Rule", Problemos 93: 70-80.

(2018c). "Philosophers and Scientists are Social Epistemic Agents", Social Epistemology Review and Reply Collective 7 (6): 31-43.

(2019). "Should Scientists Embrace Scientific Realism or Antirealism?", Philosophical Forum 50 (1): 147-158.

van Fraassen, Bas (1980). The Scientific Image. Oxford: Oxford University Press.

Winther, Rasmus (2009). “A Dialogue”, Metascience 18: 370-379. 